\title{
Mathematical Model of Measuring Monitoring and Temperature Control of Growing Vegetables in Greenhouses
}

\author{
Ivan S. Laktionov $^{1 *}$, Oleksandr V. Vovna ${ }^{1}$, Maryna M. Kabanets ${ }^{2}$, Maryna A. Derzhevetska ${ }^{3}$, Anatolii A. Zori ${ }^{1}$ \\ ${ }^{1}$ Department of Electronic Engineering, Faculty of Computer-Integrated Technologies, Automatization, Electrical Engineering \\ and Radio Electronics, SHEE' Donetsk National Technical University' of the Ministry of Education and Science of Ukraine, \\ Shybankova sq., 2, Pokrovsk UA85300, Ukraine \\ ${ }^{2}$ Language Training Department, Faculty of Computer-Integrated Technologies, Automatization, Electrical Engineering and \\ Radio Electronics, SHEE' Donetsk National Technical University' of the Ministry of Education and Science of Ukraine, \\ Shybankova sq., 2, Pokrovsk UA85300, Ukraine \\ ${ }^{3}$ Department of Medical Physics and Information Technology, Donetsk National Medical University, Railway Station str., 27, \\ Lyman UA84401, Ukraine
}

Corresponding Author Email: ivan.laktionov@donntu.edu.ua

https://doi.org/10.18280/ijdne.150306

Received: 5 February 2020

Accepted: 17 February 2020

\section{Keywords:}

energy balance, functional diagram, heat energy, greenhouse complex, microclimate, temperature

\begin{abstract}
The main purpose of the article is to improve the mathematical model of the process of computerized measuring monitoring and adaptive fuzzy control of temperature modes of growing crops in greenhouse conditions. The results of the research were obtained using methods of physical and mathematical modelling, theory of differential equations of mathematical physics, theory of thermal conductivity, methods of structuralalgorithmic synthesis of complex technical systems. The main purpose of the article was achieved by taking into account types and periods of vegetation of crops and factors of seasonality and engineering design of greenhouses, which allowed substantiating the functional diagram of the system of monitoring and control of temperature in the growing zone. The article establishes regularities of influence of natural sources and technical components of heat energy inputs and losses in greenhouses taking into account current requirements for technological modes of greenhouse operating, which allowed estimating the range of total specific heat energy sufficient for the production. Promising areas for further research of the developed model were proposed in order to increase the integral efficiency of greenhouse farms. The obtained research results can be used as a scientific and applied basis for substantiating ways to optimize energy consumption of industrial greenhouses.
\end{abstract}

\section{INTRODUCTION}

\subsection{Relevance of the research topic}

One of the prerequisites for ensuring good nutrition of the population is uniform introduction of fresh vegetables and fruits into the diet throughout the year [1]. Cost-effective and technically efficient functioning of industrial greenhouse complexes can contribute to the solution of the problem of seasonality of domestic vegetable production. In general, profitability of vegetable growing on protected grounds can be expressed in terms of energy intensity of production to the rate, quality, and volume of output greenhouse products. In order to ensure competitiveness of greenhouse enterprises in temperate and cold climates with a relatively high cost of energy, it is imperative to solve the problems of optimal and adaptive temperature control of cultivation using contemporary achievements in the field of digital, microprocessor, sensor, and information technology [2, 3]. Thus, conducting studies to justify the requirements for hardware and software for the subsystems of monitoring and control of greenhouse heating systems by mathematical modelling methods is an urgent scientific and applied task.
The scientific novelty of the obtained research results consists in the development of the nonlinear mathematical model of the process of measuring monitoring and adaptive control of temperature modes of cultivation by taking into account the types and periods of crops, as well as seasonality and climatic features of greenhouse locations. This fact allows to optimize plant growing modes in greenhouse conditions.

\subsection{Analysis and generalization of known research results}

At present, the problem of developing and substantiating mathematical models for monitoring and control of the temperature in the greenhouse growing area has been sufficiently addressed from theoretical and practical points of view. For example, the authors [4-8] propose to consider a greenhouse as a nonlinear system in which temperature is a dynamic characteristic and can be estimated on the basis of the energy balance equation. In the articles [9, 10] physical and mathematical foundations of forecasting the temperature dynamics in greenhouses are grounded on the basis of adaptive measuring monitoring of the greenhouse indoor microclimate and external climatic factors. In articles [11-13], 
the basic approaches to the implementation of simulation models of fuzzy control of temperature modes of cultivation on the basis of differential equations of heat and mass transfer are presented. In articles [14-16] basic scientific and theoretical provisions concerning physical, mathematical and simulation modelling of industrial greenhouse microclimate with the use of modern hardware and software solutions to the construction of computerized systems of monitoring and control of technological modes of crop cultivation on the protected grounds are presented. The results of the development of dynamic models of influence of microclimate parameters on the quality of growing vegetable crops under greenhouse conditions are presented in articles [17-19], as well as the main algorithms and results of numerical solution of the proposed models.

The fact of a significant number of the studies of the greenhouse microclimate monitoring and control systems using IoT and GWT technologies $[20,21]$ has been established.

These developments allow to optimize the structural and software organizations of the monitoring and control systems of the growing crops regimes. These results can be used as a basic during development of the mathematical model of measuring monitoring and temperature control of growing vegetables in greenhouses.

Analysis and logical generalization of the known research results in the investigated subject area revealed lack of scientists' attention to the influence of types and periods of greenhouse crops vegetation, taking into account factors of climatic zones and seasonality of cultivation on technical and functional characteristics of monitoring and control of heating systems. This fact necessitates conducting research to justify the requirements for structural and algorithmic organization of such subsystems by mathematical modelling methods, which will increase economic and technical efficiency of the production process of growing vegetables in greenhouses.

\subsection{Purpose, object and structure of the research}

The main purpose of the article is to improve the mathematical model of the process of computerized measuring monitoring and adaptive temperature control of crop growing in greenhouse conditions by taking into account types and periods of crop vegetation and the seasonality factor, which will allow optimizing energy consumption of greenhouses.

The object of the study is regularities of the influence of informative parameters and destabilizing factors on the distribution of heat energy in the greenhouse growing zone.

Section 2 describes the basic materials and methods used in the development of the mathematical model; section 3 presents the basic quantitative and qualitative results of mathematical modelling of the process of temperature monitoring in greenhouses; section 4 outlines promising areas for further research; section 5 summarizes the main conclusions of the article.

\section{MATERIALS AND METHODS OF THE RESEARCH}

\subsection{General research methods}

Theoretical and experimental studies on the development and justification of the mathematical model of the process of measuring monitoring and control of temperature modes of greenhouse crop cultivation were obtained using the provisions of physical and mathematical modelling, theory of differential equations of mathematical physics, theory of thermal conductivity, structural-synthetic algorithms. The main research results were obtained in the specialized laboratories "Information and Measurement Engineering and Metrology" and "Computer Technologies and Modelling" of the Department of Electronic Engineering of SHEE "Donetsk National Technical University" using certified and standardized equipment and software.

\subsection{Basic research technique}

Measuring temperature monitoring is a dynamic process, the characteristics of which are mainly determined by the exchange of energy between the indoor greenhouse growing area and the outside environment. In this case, the mathematical modelling of thermodynamic processes occurring in the greenhouse involves establishing and solving equations of mathematical physics.

Based on the analysis of the known research results on modelling temperature modes in greenhouses, it is established that the modern engineering design of industrial greenhouse complexes allows assuming during mathematical modelling of thermodynamic processes that the greenhouse is an object with a uniform temperature distribution in the cultivation zone. Therefore, the basic equation for mathematical modelling of measuring temperature monitoring is [22]:

$$
\frac{\partial T_{\text {air in }}(t)}{\partial t}=\frac{Q_{\text {total }}(t)}{V_{\text {in }} \cdot \rho_{\text {air }} \cdot C_{\rho}}
$$

where, $T_{\text {air in }}$ is temperature inside the greenhouse, ${ }^{\circ} \mathrm{C} ; Q_{\text {total }}$ is total heat energy in the growing zone, $\mathrm{W} ; t$ is time, h.; $V_{\text {in }}$ is volume of the greenhouse growing zone, $\mathrm{m}^{3} ; \rho_{\text {air }}$ is air density, $\mathrm{kg} \cdot \mathrm{m}^{-3} ; C_{\rho}$ is specific heat of air, $\mathrm{J} \cdot \mathrm{kg}^{-1} \cdot{ }^{\circ} \mathrm{C}^{-1}$.

Temperature dynamics in greenhouses is affected by different processes of heat and mass transfer. Therefore, in order to develop a relatively accurate and adequate model describing heat distribution in the greenhouse growing zone, it is important to investigate in detail the mechanisms of these processes. Thus, the basis of the developed mathematical model is the equation of the balance of mass and energy inside the greenhouse $[11,22]$ :

$$
Q_{\text {total }}=Q_{\text {gain }}-Q_{\text {loss }}
$$

where, $Q_{\text {gain }}$ is amount of energy supplied to the greenhouse, $\mathrm{W}$; $Q_{\text {loss }}$ is amount of energy consumed in a greenhouse, W.

Tomatoes and cucumbers were selected as the basic types of greenhouse crops when designing the mathematical model. The study of the mathematical model was conducted for two typical growing seasons: before fruiting and during fruiting. The annual growing period was divided into two main cycles: autumn-winter and spring-summer.

\subsection{Sources of heat energy}

The amount of energy coming into the greenhouse is greatly influenced by the following physical processes and 
phenomena: energy from solar radiation; energy from the heating system; thermal component of energy from artificial systems of additional lighting [10, 11, 22]. Thus, in general, the amount of the energy supplied to the greenhouse can be calculated by the formula:

$$
Q_{\text {gain }}=Q_{s}+Q_{h}+Q_{l}
$$

where, $Q_{s}$ is useful solar energy supplied to the greenhouse, $\mathrm{W} ; Q_{h}$ is heat energy from the heating system, W; $Q_{l}$ is thermal component of energy from artificial systems of additional lighting, $\mathrm{W}$.

One of the most important factors determining the input of heat energy to the greenhouse is solar radiation. The heat energy supplied to the greenhouse from the sun can be estimated by the following relation $[23,24]$ :

$$
Q_{s}=A_{g} \cdot \gamma \cdot \tau \cdot I_{\text {total }}
$$

where, $A_{g}$ is the greenhouse surface area (roof and sidewalls), $\mathrm{m}^{2} ; \gamma$ is the constant of the fraction of solar radiation entering the greenhouse and causing the temperature increase, relative units; $\tau$ is the greenhouse surface capacity, relative units; $I_{\text {total }}$ is the solar energy falling on the greenhouse surface, $\mathrm{W} \cdot \mathrm{m}^{-2}$.

At present, there are several theoretical and empirical models that describe the dynamics of solar radiation. On the basis of the analysis of the obtained simulation data, the necessity of refining the model of solar radiation distribution with consideration of seasonal and daily dynamics of the solar radiation [25] for temperate continental climate was established. For the spring-summer period, the average value of daylight hours is equal to 13 hours (from 6 a.m. to 7 p.m.) and 9 hours for autumn-winter period (from 8 a.m. to 4 p.m.) for GMT+3 time zone. On this basis, the analytic expression for describing the daily dynamics of the solar radiation, taking into account the seasonality, is as follows:

- For the spring-summer cultivation cycle:

$$
\left\{\begin{array}{l}
I_{\text {total }}=\left|k_{\text {decr }}\left[I_{S C} \cdot(\sin (\omega t-\varphi)+\sin (\omega))\right]\right|, 6 n \leq t \leq 19 n ; \\
I_{\text {total }}=0, \text { otherwise, }
\end{array}\right.
$$

- for the autumn-winter cultivation cycle:

$$
\left\{\begin{array}{l}
I_{\text {total }}=\left|k_{\text {decr }}\left[I_{S C} \cdot(\sin (\omega t-\varphi)+\sin (\omega))\right]\right|, 8 n \leq t \leq 16 n \\
I_{\text {total }}=0, \text { otherwise, }
\end{array}\right.
$$

where, $k_{d e c r}$ is the coefficient of the solar radiation attenuation, which varies in the range from 0.47 to 0.85 , relative units; $I_{s c}$ is the solar constant equal to $1367 \mathrm{~W} \cdot \mathrm{m}^{-2} ; \omega$ is cyclic frequency of change in the solar radiation, defined as $2 \pi / 24$, rad.; $\varphi$ is the argument of sinusoidal variation of solar radiation (for spring-summer period - 13 hours, for autumnwinter -8 hours, $(\mathrm{GMT}+3))$; $n$ is the continuous number of the day in the calendar year.

When estimating the value of the useful solar energy supplied to the greenhouse, the numerical values of the parameters were assigned in accordance with Table 1. Typical sizes of greenhouses were selected based on current recommendations for modern engineering design.

The heat transfer rate from the stationary heating system to the air of the growing zone, depending on the structural characteristics can be calculated by the formula $[10,23]$ :

$$
Q_{h}=m_{\text {h.c. }} \cdot c_{\text {h.c. }} \cdot\left(T_{\text {direct }}-T_{\text {back }}\right)
$$

where, $m_{h . c}$ is heat carrier consumption, $\mathrm{kg} \cdot \mathrm{s}^{-1} ; c_{h . c}$ is specific heat capacity of the heat carrier, $\mathrm{J} \cdot \mathrm{kg}^{-1 .}{ }^{\circ} \mathrm{C}^{-1} ; T_{\text {direct }}$ is the heat carrier supply temperature, ${ }^{\circ} \mathrm{C} ; T_{b a c k}$ is the temperature of the heat carrier removed from the heating system, ${ }^{\circ} \mathrm{C}$.

During the estimation of the value of heat energy coming into the greenhouse from the stationary heating systems, the numerical values of the parameters were assigned in accordance with Table 2 .

The thermal energy component of artificial light systems can be estimated by taking into account the existing recommendations [26] by the formula:

$$
Q_{l}=E_{l} \cdot F_{l} \cdot q_{l} \cdot \eta_{l}
$$

where, $E_{l}$ is the required level of illumination of the growing zone, $1 \mathrm{x} ; F_{l}$ is the area of the greenhouse under lying surface, which ranges from 0.2 to 0.3 for greenhouses of different design, $\mathrm{m}^{2} ; q_{l}$ is the specific heat release indicator, $\mathrm{W} \cdot 1 \mathrm{x}^{-1} \cdot \mathrm{m}^{-2}$, $\eta_{l}$ is the share of heat entering the growing zone, relative units.

In estimating the value of the heat energy supplied to the greenhouse from stationary specialized Phyto-LED artificial illumination systems, the numerical values of the parameters were assigned in accordance with Table 3.

Table 1. Assigned values of useful solar energy modelling

\begin{tabular}{ccc}
\hline Parameter & $\begin{array}{c}\text { Accepted } \\
\text { value }\end{array}$ & Units \\
\hline $\begin{array}{c}\text { Surface area }\left(A_{g}\right) \\
\text { (typical values for temperate } \\
\text { continental climate) }\end{array}$ & $1500 ; 3000$ & $\mathrm{~m}^{2}$ \\
$\begin{array}{c}\text { Solar radiation fraction constant }(\gamma) \\
\text { Greenhouse surface capacity }(\tau)\end{array}$ & 0.5 & $\begin{array}{c}\text { rel. units } \\
\text { Sol. units }\end{array}$ \\
$\begin{array}{c}\text { Soladiation attenuation } \\
\text { coefficient }\left(k_{\text {decr }}\right)\end{array}$ & 0.7 & \begin{tabular}{c} 
rel. units \\
\hline
\end{tabular} \\
\hline
\end{tabular}

Table 2. Assigned values of modelling heat energy from greenhouse heating systems

\begin{tabular}{ccc}
\hline Parameter & $\begin{array}{c}\text { Accepted } \\
\text { value }\end{array}$ & Units \\
\hline $\begin{array}{c}\text { Consumption of heat carrier }\left(m_{\text {h.c. }}\right) \\
\text { Specific heat capacity of heat carrier } \\
(\text { ch.c. })\end{array}$ & 10 & $\mathrm{~kg} \cdot \mathrm{s}^{-1}$ \\
$\begin{array}{c}\mathrm{J} \cdot \mathrm{kg}^{-} \\
\text {Permissible difference between }\end{array}$ & 4200 & ${ }^{\circ} \mathrm{C}^{-1}$ \\
$\begin{array}{c}\text { temperatures of the forward and reverse } \\
\text { branches of the heating system } \\
\left(T_{\text {direct }}-T_{\text {back }}\right)\end{array}$ & 10 & ${ }^{\circ} \mathrm{C}$ \\
\hline
\end{tabular}

Table 3. Assigned values of modelling heat energy from artificial light systems

\begin{tabular}{ccc}
\hline Parameter & $\begin{array}{c}\text { Accepted } \\
\text { value }\end{array}$ & Units \\
\hline $\begin{array}{c}\text { Minimum required level of } \\
\text { illumination }\left(E_{l}\right)\end{array}$ & 6315 & $1 \mathrm{x}$ \\
$\begin{array}{c}\text { The area of the greenhouse } \\
\text { underlying surface }\left(F_{l}=A_{\mathrm{g}} / 4\right)\end{array}$ & $375 ; 750$ & $\mathrm{~m}^{2}$ \\
$\begin{array}{c}\text { Specific heat release rate }(q l) \\
\text { Share of heat entering the } \\
\text { growing zone }\left(\eta_{l}\right)\end{array}$ & 0.018 & $\mathrm{~W} \cdot \mathrm{lx}^{-1} \cdot \mathrm{m}^{-2}$ \\
\hline
\end{tabular}




\subsection{Sources that cause heat loss}

Losses of heat energy in the greenhouse are largely due to the following processes and phenomena: heat loss due to thermal conductivity; heat loss due to soil absorption capacity; heat transfer due to ventilation and infiltration; condensation heat transfer $[10,11,22]$. Therefore, in general terms, the amount of energy lost in the greenhouse can be calculated as follows:

$$
Q_{\text {loss }}=Q_{k}+Q_{g}+Q_{v}+Q_{i}+Q_{c}
$$

where, $Q_{k}$ is heat loss due to thermal conductivity, W; $Q_{g}$ is heat loss due to soil absorption capacity, W; $Q_{v}$ is heat transfer through ventilation, $\mathrm{W} ; Q_{i}$ is heat transfer through infiltration, $\mathrm{W} ; Q_{c}$ is condensation heat transfer, $\mathrm{W}$.

Based on the analysis of the dependence (9), it can be seen that the loss of heat energy is caused by a considerable number of physical processes, one of which is the heat loss due to thermal conductivity. This component of the energy loss can be calculated using the following equation [22]:

$$
Q_{k}=h \cdot A_{g} \cdot\left(T_{\text {air in }}-T_{\text {air out }}\right)
$$

where, $h$ is the heat transfer coefficient, $\mathrm{W} \cdot \mathrm{m}^{-2} \cdot{ }^{\circ} \mathrm{C}^{-1} ; A_{g}$ is the greenhouse surface area, $\mathrm{m}^{2} ; T_{\text {air }}$ in is temperature in the greenhouse, ${ }^{\circ} \mathrm{C} ; T_{\text {air out }}$ is ambient temperature, ${ }^{\circ} \mathrm{C}$.

The coefficient of heat transfer, which is a part of the Eq. (10), can be calculated depending on the speed of movement of air flows in the greenhouse [22] by the formula:

$$
h=2,8+1,2 \cdot v_{\text {air in }}
$$

where, $v_{\text {air in }}$ is the velocity of air flow, $\mathrm{m} \cdot \mathrm{c}^{-1}$.

The optimum temperature inside the greenhouse depends on the types and periods of vegetation of the crops grown. Statistics on the temperature dynamics over the last calendar year in Ukraine were obtained according to the official data of the Ukrainian Hydrometeorological Centre: for the autumn-winter cycle it is $+3.77^{\circ} \mathrm{C}$, for the spring-summer cycle it is $+15.6^{\circ} \mathrm{C}$.

Therefore, the numerical values of the parameters in accordance with Table 4 are assigned when estimating the values of heat energy losses caused by the heat transfer effect.

The next physical process to be taken into account when estimating heat losses in the greenhouse is the soil absorbing capacity. The estimated value of the heat loss due to the soil absorption capacity can be calculated by the formula $[11,22]$ :

$$
Q_{g}=\frac{k_{g}}{Z_{g}} \cdot F_{l} \cdot\left(T_{\text {air in }}-T_{\text {soil }}\right)
$$

where, $k_{g}$ is the coefficient of soil thermal conductivity, $\mathrm{W}$. $\mathrm{m}^{-1} \cdot{ }^{\circ} \mathrm{C}^{-1} ; Z_{g}$ is thickness of the soil layer, $\mathrm{m} ; F_{l}$ is the area of the greenhouse underlying surface, $\mathrm{m}^{2} ; T_{\text {air }}$ in is greenhouse air temperature, ${ }^{\circ} \mathrm{C} ; T_{\text {soil }}$ is soil temperature, ${ }^{\circ} \mathrm{C}$.

The calculation of the heat losses was carried out taking into account the current requirements for temperature modes of the gas-air environment and the greenhouse soil, the thickness of the soil layer and typical sizes of industrial greenhouse complexes, as shown in Table 5.
Table 4. Assigned values of modelling heat energy losses due to thermal conductivity

\begin{tabular}{ccc}
\hline Parameter & Accepted value & Units \\
\hline Velocity of the air flow $($ vair in $)$ & 1 & $\mathrm{~m} \cdot \mathrm{s}^{-1}$ \\
Surface area $\left(A_{g}\right)$ & $1500 ; 3000$ & $\mathrm{~m}^{2}$ \\
Average ambient temperature $\left(T_{\text {air out }}\right)$ & $+3.77 ;+15.6$ & ${ }^{\circ} \mathrm{C}$ \\
\hline
\end{tabular}

Table 5. Assigned values of modelling heat energy losses due to soil absorption capacity

\begin{tabular}{ccc}
\hline Parameter & $\begin{array}{c}\text { Accepted } \\
\text { value }\end{array}$ & Units \\
\hline $\begin{array}{c}\text { Soil thermal conductivity } \\
\text { coefficient }\left(k_{g}\right)\end{array}$ & 1.52 & $\mathrm{~W} \cdot \mathrm{m}^{-1 .{ }^{\circ} \mathrm{C}^{-1}}$ \\
$\begin{array}{c}\text { Area of the greenhouse } \\
\text { underlying surface }\left(F_{l}\right)\end{array}$ & $375 ; 750$ & $\mathrm{~m}^{2}$ \\
$\begin{array}{c}\text { Thickness of the soil layer }\left(Z_{g}\right) \\
\text { Permissible temperature } \\
\text { difference }\left(T_{\text {air in }}-T_{\text {soil }}\right)\end{array}$ & 0.5 & $\mathrm{~m}$ \\
\hline
\end{tabular}

The effects of heat loss from the crop growing zone under the influence of heat and wind pressure are ventilation (forced and natural) $\left(Q_{v}\right)$ and infiltration $\left(Q_{i}\right)$. Estimation of the heat loss through ventilation can be performed by the following formula $[11,27]$ :

$$
Q_{v}=\frac{r_{v} \cdot V_{g} \cdot k_{\text {air }} \cdot\left(T_{\text {air in }}-T_{\text {air out }}\right) \cdot C_{\rho} \cdot \rho_{\text {air }}}{3600}
$$

where, $r_{v}$ is percentage of opening mechanisms of the ventilation system, relative units; $V_{g}$ is greenhouse volume, $\mathrm{m}^{3} ; k_{\text {air }}$ is multiplicity of air exchange, $\mathrm{h}^{-1} ; C_{\rho}$ is specific heat of air, $\mathrm{J} \cdot \mathrm{kg}^{-1 .}{ }^{\circ} \mathrm{C}^{-1} ; T_{\text {air in }}$ is greenhouse temperature, ${ }^{\circ} \mathrm{C} ; T_{\text {air out }}$ is ambient temperature, ${ }^{\circ} \mathrm{C} ; \rho_{\text {air }}$ is air density, $\mathrm{kg} \cdot \mathrm{m}^{-3}$.

The numerical value of the heat loss indicator due to the infiltration process, which is caused by the greenhouse surface density, can be estimated by the following formula [11]:

$$
Q_{i}=\frac{0,5 \cdot V_{g} \cdot k_{\text {air }} \cdot\left(T_{\text {air in }}-T_{\text {air out }}\right)}{3600}
$$

Thus, the total heat loss $\left(Q_{v+i}\right)$ caused by the processes of ventilation and infiltration can be found by the formula:

$$
\begin{aligned}
& Q_{v+i}=\frac{r_{v} \cdot V_{g} \cdot k_{\text {air }} \cdot\left(T_{\text {air in }}-T_{\text {air out }}\right) \cdot C_{\rho} \cdot \rho_{\text {air }}}{3600}+ \\
& +\frac{0,5 \cdot V_{g} \cdot k_{\text {air }} \cdot\left(T_{\text {air in }}-T_{\text {air out }}\right)}{3600}
\end{aligned}
$$

Numerous parameters were assigned during the simulation of the heat loss due to the processes of ventilation and infiltration of the greenhouse, including seasonal factors, climatic characteristics of the region, types and periods of crop vegetation, as well as the engineering design of greenhouses, as shown in Table 6.

The effect of condensation, which is caused by the constant release of moisture by plants, leads to the restriction of the supply of the heat energy to the greenhouse growing zone. The heat energy losses due to the effect of condensation on the greenhouse surface can be numerically estimated by taking into account the geometric characteristics 
of greenhouses and the seasonality factor according to the following formula [23]:

$$
Q_{c}=C_{c} \cdot L_{v} \cdot A_{g}
$$

where, $C_{c}$ is rate of condensation on the greenhouse surface, which is due to the difference between external and internal temperature and humidity, $\mathrm{kg} \cdot \mathrm{s}^{-1} \cdot \mathrm{m}^{-2} ; L_{v}$ is enthalpy of

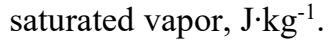

Table 6. Assigned values of modelling heat energy losses due to ventilation and infiltration

\begin{tabular}{|c|c|c|}
\hline Parameter & $\begin{array}{l}\text { Accepted } \\
\text { value }\end{array}$ & Units \\
\hline Specific heat capacity of air $\left(C_{\rho}\right)$ & 1010 & $\begin{array}{l}\mathrm{J} \cdot \mathrm{kg}^{-} \\
1 .{ }^{\circ} \mathrm{C}^{-1}\end{array}$ \\
\hline Average ambient temperature $\left(T_{\text {air out }}\right)$ & $+3.77 ;+15.6$ & ${ }^{\circ} \mathrm{C}$ \\
\hline Air density $(\rho$ air $)$ & 1.292 & $\mathrm{~kg} \cdot \mathrm{m}^{-3}$ \\
\hline Multiplicity of air exchange $($ kair $)$ & 2 & $\mathrm{~h}^{-1}$ \\
\hline Greenhouse volume $\left(V_{g}=A_{g} \cdot h_{g} / 4\right)$ & $1875 ; 3750$ & $\mathrm{~m}^{3}$ \\
\hline $\begin{array}{l}\text { Percentage of opening the mechanisms } \\
\text { of the ventilation system }\left(r_{v}\right)\end{array}$ & 0.6 & rel. units \\
\hline
\end{tabular}

Estimates of the rate of condensation on the greenhouse surface were obtained by the researchers [22] for a temperate continental climate, as shown in Table 7 .

Table 7. Assigned values of modelling of heat energy losses due to condensation

\begin{tabular}{ccc}
\hline Parameter & Accepted value & Units \\
\hline Surface area $\left(A_{g}\right)$ & $1500 ; 3000$ & $\mathrm{~m}^{2}$ \\
Saturated vapor enthalpy $\left(L_{v}\right)$ & $2.45 \cdot 10^{6}$ & $\mathrm{~J} \cdot \mathrm{kg}^{-1}$ \\
Condensation rate in winter $\left(C_{c}\right)$ & $2.5 \cdot 10^{-6}$ & $\mathrm{~kg} \cdot \mathrm{s}^{-1} \cdot \mathrm{m}^{-2}$ \\
\hline
\end{tabular}

The authors of the study [22] also found that the energy losses due to condensation increase if the greenhouse surface temperature is lower than the dew point temperature of the indoor air. Therefore, taking into account this effect, we can assume that the condensation rate in the spring-summer growing cycle is zero.

\section{RESEARCH RESULTS}

\subsection{Quantitative and qualitative modelling results}

When estimating the value of the useful solar energy according to formulas (4)-(6), which enters the greenhouse, the results were obtained in the normalized to the maximum energy value (for greenhouses with the area of $1500 \mathrm{~m}^{2}-$ $378.5 \mathrm{~kW}$, for greenhouses with the area of $3000 \mathrm{~m}^{2}-757$ $\mathrm{kW}$ ), as shown in Figure 1. The obtained simulation results, which are shown in Figure 1, proved the need to take into account the seasonal and daily dynamics of the solar radiation when estimating the heat energy entering the greenhouse growing zone from the sun. The estimated value of the heat energy entering the greenhouse growing zone from stationary heat supply systems, which is calculated by formula (7), is $420 \mathrm{~kW}$. The obtained results of calculations of heat energy component from the heat supply systems proved the necessity of their account during the research of the mathematical model of measurement monitoring of the growing zone temperature of industrial greenhouses.

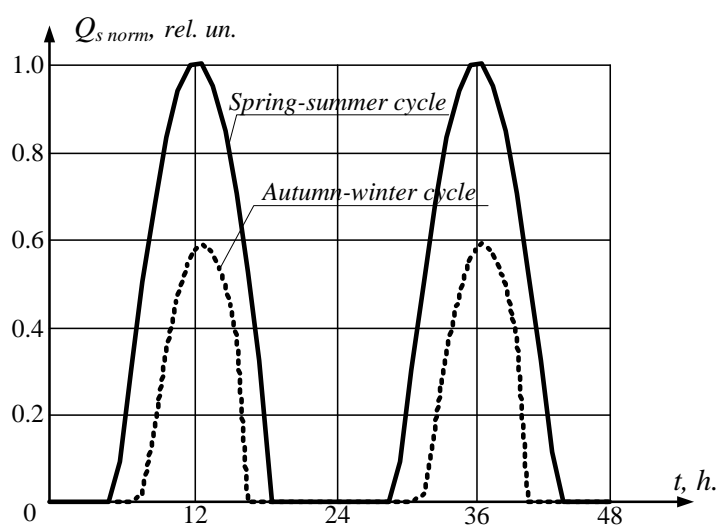

Figure 1. Normalized characteristics of the distribution of the useful solar energy

When estimating the value of the heat energy entering the greenhouse from the stationary artificial lighting systems using formula (8), the following numerical results were established: $42.6 \mathrm{~kW}$ - for greenhouses with the area of $1,500 \mathrm{~m}^{2} ; 85.2 \mathrm{~kW}$ - for greenhouses with the area of 3,000 $\mathrm{m}^{2}$.

Therefore, the total amount of the heat energy supplied to the greenhouse, taking into account the above components, which are calculated by formulas $(4)-(8)$, can be estimated by formula (3). The simulation of the process of heat energy supply to greenhouses also takes into account the requirements for duration of the photoperiod of artificial lighting of greenhouse crops, which must be at least 16 hours. Thus, at the qualitative level, the heat input to the greenhouse is as follows: the useful solar energy - see Figure 1; the heat energy from the heating system -24 hours a day; the heat energy from artificial lighting systems - from 4 a.m. to 8 p.m. $(\mathrm{GMT}+3)$. The obtained simulation results are normalized to the maximum energy value (for greenhouses with the area of $1500 \mathrm{~m}^{2}$ is equal $Q_{\text {gain } \max }=841.1 \mathrm{~kW}$, for greenhouses with the area of $3000 \mathrm{~m}^{2}-Q_{\text {gain } \max }=1262.2 \mathrm{~kW}$ ). The normalized graph of energy distribution taking into account the areas of greenhouses is shown in Figure 2.

Based on the analysis of the simulation results shown in Figure 2, the estimated ranges of the total heat energy changes for greenhouses with typical sizes of 1500 and 3000 $\mathrm{m}^{2}$, respectively, are: from 420 to $841.1 \mathrm{~kW}$ and from 420 $\mathrm{kW}$ to $1262.2 \mathrm{~kW}$. The average rate of the heat energy increase / decrease was also established: for greenhouses with the area of $1500 \mathrm{~m}^{2}$ it is $46.8 \mathrm{~kW} \cdot \mathrm{h}^{-1}$; for greenhouses with the area of $3000 \mathrm{~m}^{2}-93.6 \mathrm{~kW} \cdot \mathrm{h}^{-1}$.

The obtained graph of distribution of the estimated values of the heat energy losses on the basis of formulas (10) and (11) due to the heat transfer effect taking into account seasonality, geometric sizes of greenhouses and types and periods of vegetation of crops is shown in Figure 3.

The results of the calculations shown in Figure 3 prove the need to take into account the effect of the heat energy transfer from the growing zone to the environment during the mathematical modelling of the process of temperature monitoring.

The obtained results of the calculations of the heat energy losses due to the soil absorption capacity, which are estimated by formula (12), are as follows: for greenhouses with the area of $1500 \mathrm{~m}^{2}$ it is $3.42 \mathrm{~kW}$, for greenhouses with the area of $3000 \mathrm{~m}^{2}-6.84 \mathrm{~kW}$, which is from 5 to $20 \%$ of energy losses due to the thermal conductivity of the 
greenhouse surface and requires further consideration during the mathematical modelling of the temperature monitoring process.

The obtained graphical view of the distribution of estimated values of the total heat losses due to ventilation effects (natural and mechanical) and infiltration, taking into account seasonality, geometric sizes of greenhouses and types and periods of vegetation on the basis of formula (15) is shown in Figure 4.

The results of the numerical simulations shown in Fig. 4, prove the need to take into account the effect of heat losses due to the ventilation and infiltration during the mathematical modelling of the process of temperature monitoring.

The results of calculations of the heat energy losses due to the effect of condensation based on formula (16) are as follows: for spring-summer cycle $Q_{c}=0 \mathrm{~W}$, for autumnwinter $-12.7 \mathrm{~kW}$ (for greenhouses with the area of $1500 \mathrm{~m}^{2}$ ) and $25.7 \mathrm{~kW}$ (for greenhouses with the area of $3000 \mathrm{~m}^{2}$ ). The results of the calculations prove the need to take into account the effect of condensation during the mathematical modelling of the process of temperature monitoring of the greenhouse growing zone.

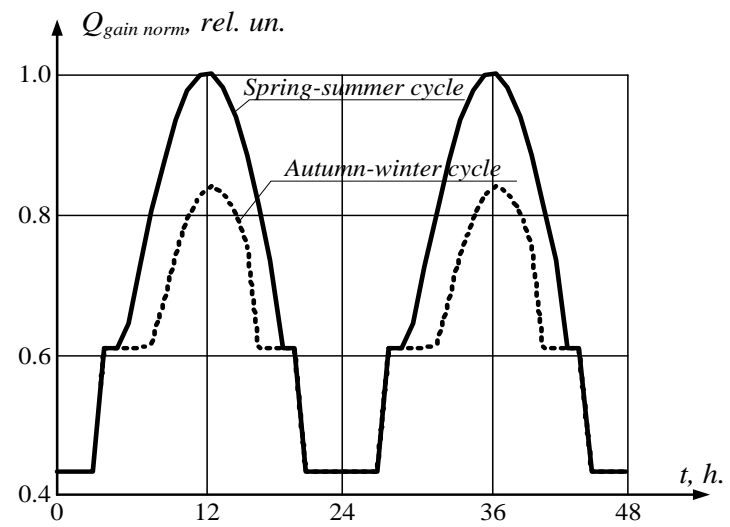

(a) $A_{g}=1500 \mathrm{~m}^{2}$

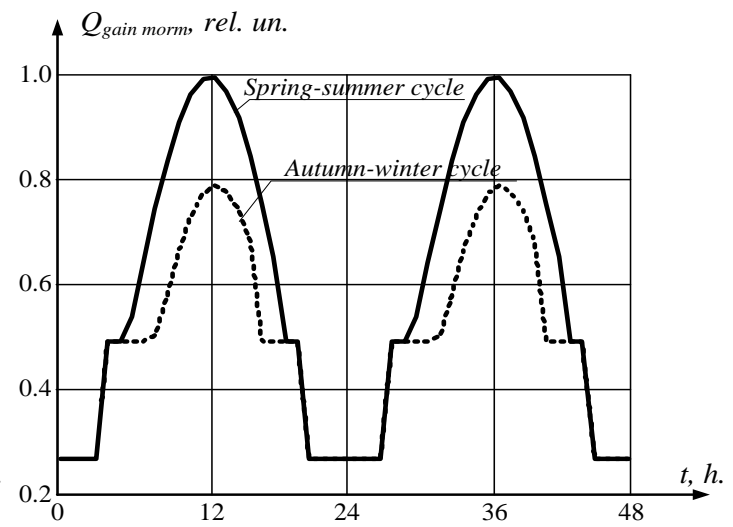

(b) $A_{g}=3000 \mathrm{~m}^{2}$

Figure 2. Normalized characteristics of the distribution of the heat energy entering the greenhouse

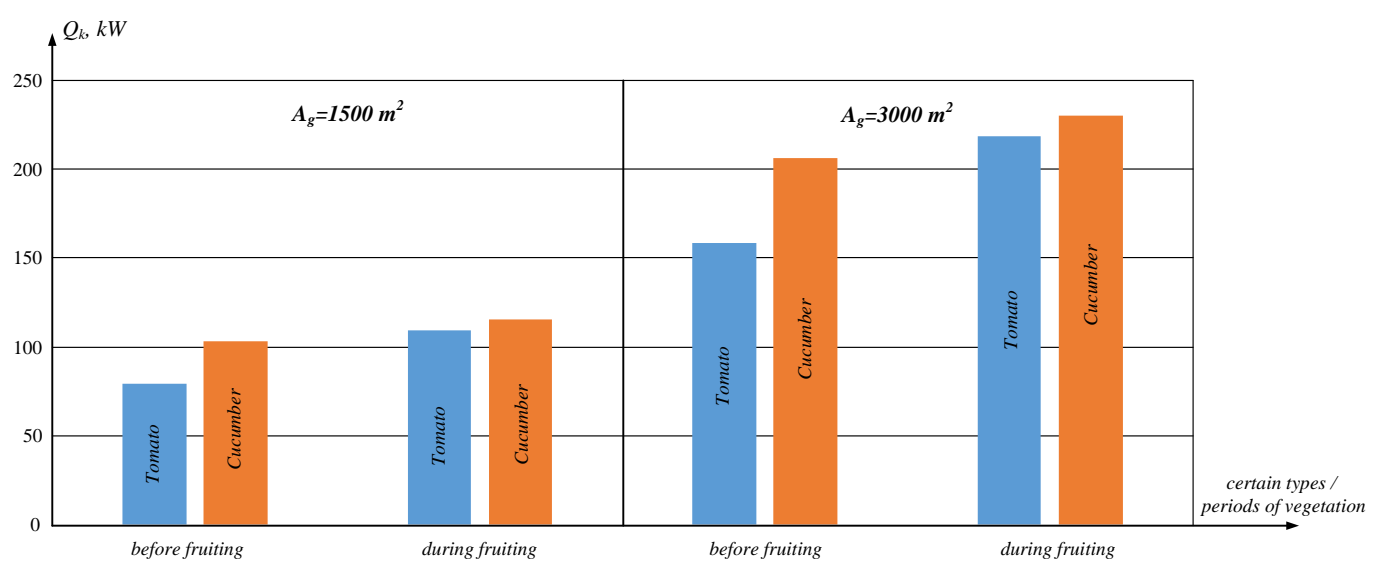

(a) Autumn-winter cycle

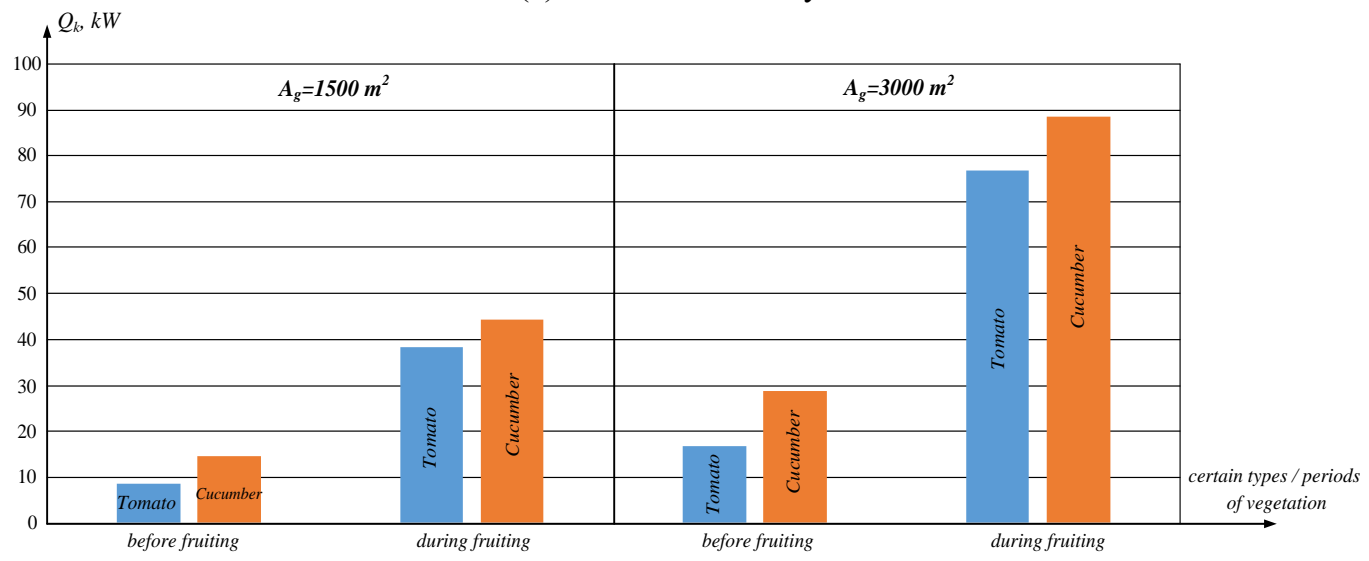

(b) Spring-summer cycle

Figure 3. Heat energy losses due to the heat transfer effect 


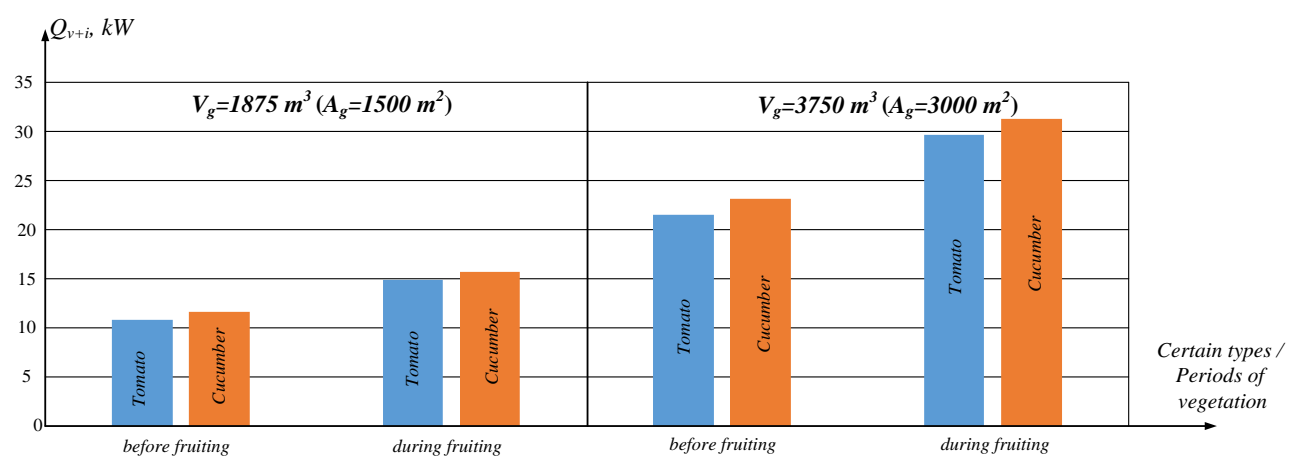

(a) Autumn-winter cycle

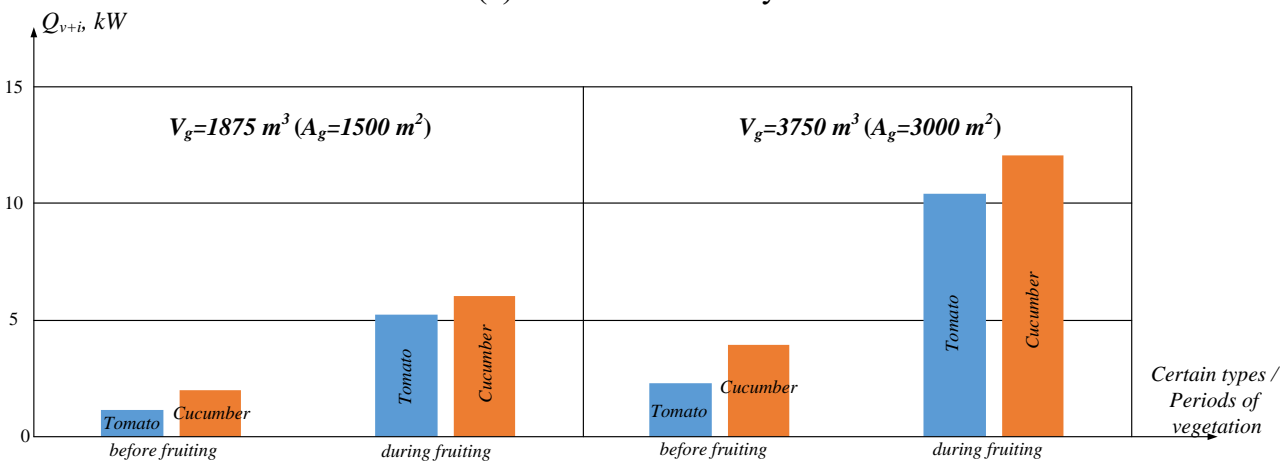

(b) Spring-summer cycle

Figure 4. Heat energy losses due to the effects of ventilation and infiltration

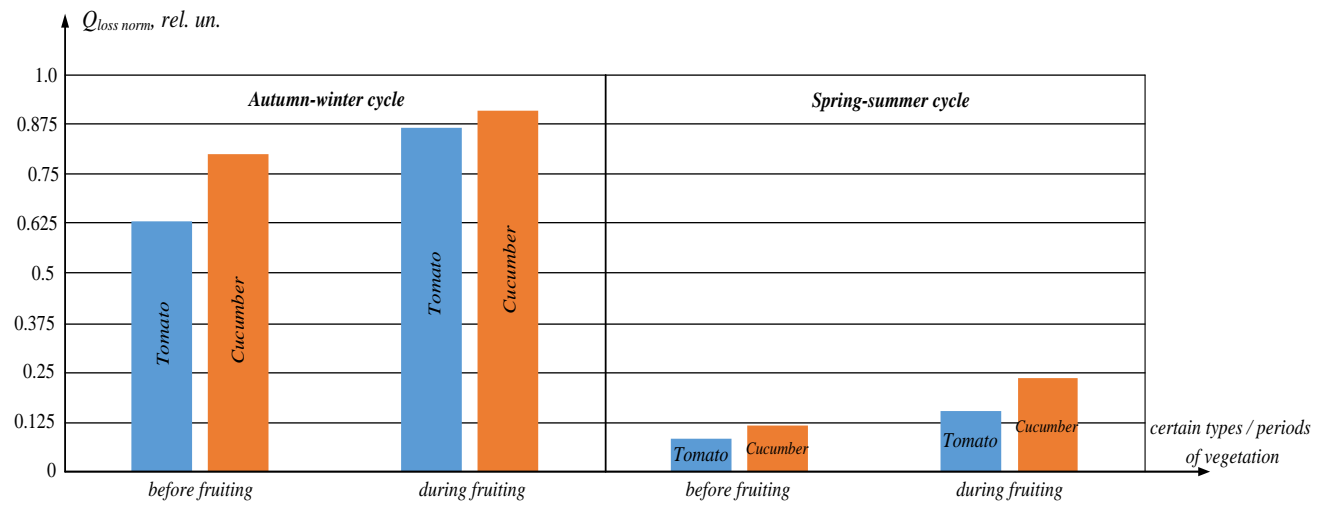

Figure 5. Total heat energy losses

Therefore, the total amount of the heat energy lost in the greenhouse due to the effects of soil thermal conductivity, soil absorption capacity, ventilation, infiltration and condensation can be estimated by formula (9) based on the results of calculations by formulas (10) - (16). While modelling the process of heat energy losses from the greenhouse, the regulated requirements for the engineering design of greenhouses, the temperature-humidity modes of growing greenhouse crops and the seasonality factor were taken into account. The obtained results of modelling the distribution of total heat losses in the normalized graphical form (for greenhouses with the area of $1500 \mathrm{~m}^{2}$ it is equal to $Q_{\text {loss max }}=160 \mathrm{~kW}$, for greenhouses with the area of $3000 \mathrm{~m}^{2}-$ $Q_{\text {loss } \max }=320 \mathrm{~kW}$ ) are shown in Figure 5 .

Based on the analysis of the modelling results shown in Figure 5, the estimated ranges of changes in total heat loss for greenhouses with typical sizes of 1500 and $3000 \mathrm{~m}^{2}$, respectively, are: from 13.1 to $145.8 \mathrm{~kW}$ and from 26.2 to $291.6 \mathrm{~kW}$, taking into account the seasonality factors and types and vegetation periods of growing crops.

Thus, taking into account the obtained values of the components of the input and losses of the heat energy in the greenhouse, the total heat energy (2) in the growing zone can be calculated. The estimated range of changes in the heat energy in the growing zone is obtained taking into account the following factors: seasonality, daily dynamics of solar radiation intensity, current requirements for temperature and humidity of certain types and periods of vegetation, engineering design of industrial greenhouses. The obtained results of mathematical modelling of heat energy dynamics in the graphical form are shown in Figures 6 and 7.

Based on the obtained data, which are shown in Figures 6 and 7 , the dynamics of temperature in greenhouses by formula (1) can be estimated.

The differential equation is solved analytically under the following initial conditions: $T_{\text {air in }}(0)=+3.77^{\circ} \mathrm{C}-$ for the autumn-winter cycle and $T_{\text {air in }}(0)=+15.6^{\circ} \mathrm{C}-$ for the springsummer cycle. The obtained results of modelling the temperature dynamics in the growing zone for cucumbers and tomatoes, taking into account the vegetation periods and seasonality are shown in Figures 8 and 9. 


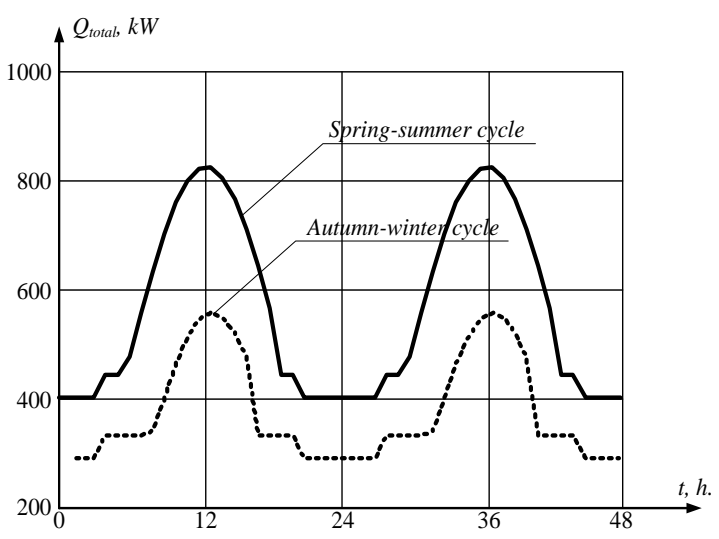

(a) before fruiting $\left(A_{g}=1500 \mathrm{~m}^{2}\right)$

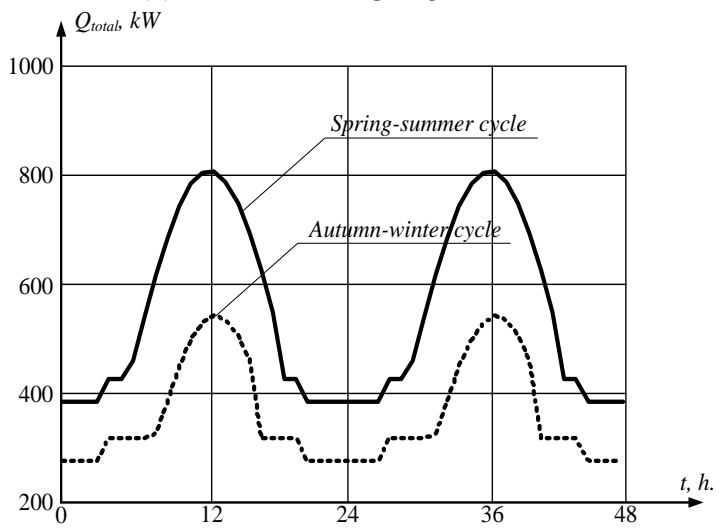

(b) during fruiting $\left(A_{g}=1500 \mathrm{~m}^{2}\right)$

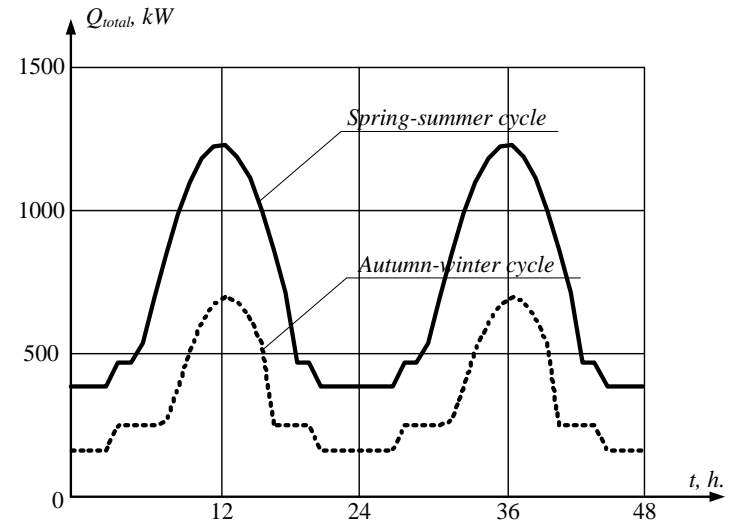

(c) before fruiting $\left(A_{g}=3000 \mathrm{~m}^{2}\right)$

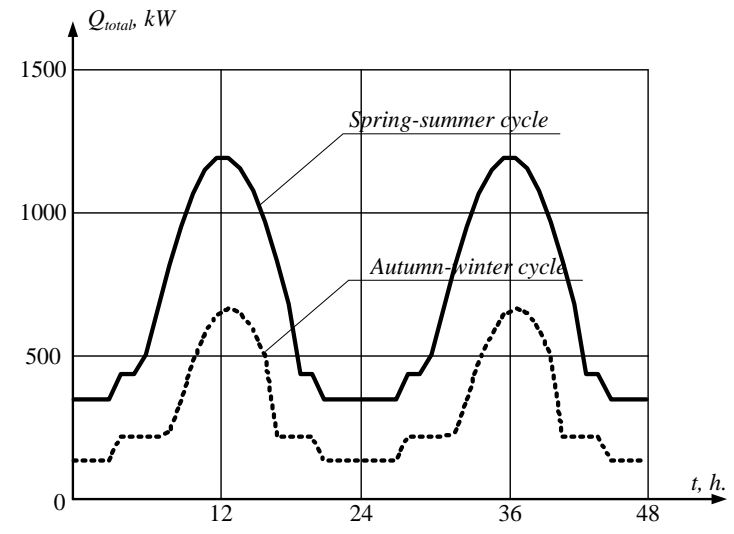

(d) during fruiting $\left(A_{g}=3000 \mathrm{~m}^{2}\right)$

Figure 6. Dependence of heat energy distribution in the greenhouse during cucumber growing

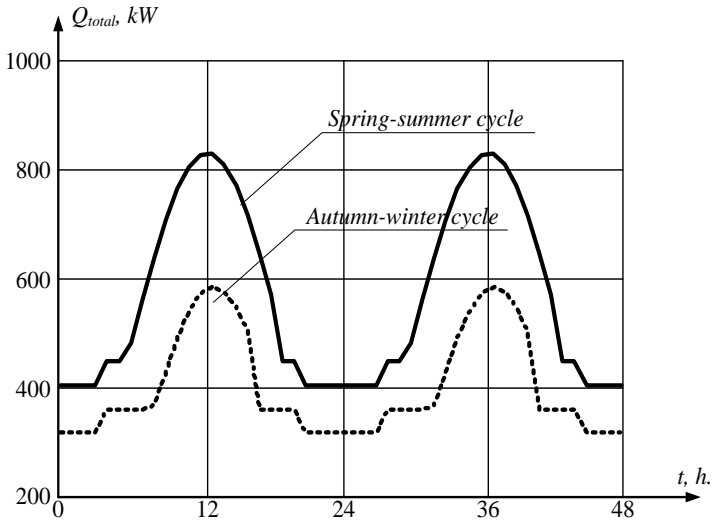

(a) before fruiting $\left(A_{g}=1500 \mathrm{~m}^{2}\right)$

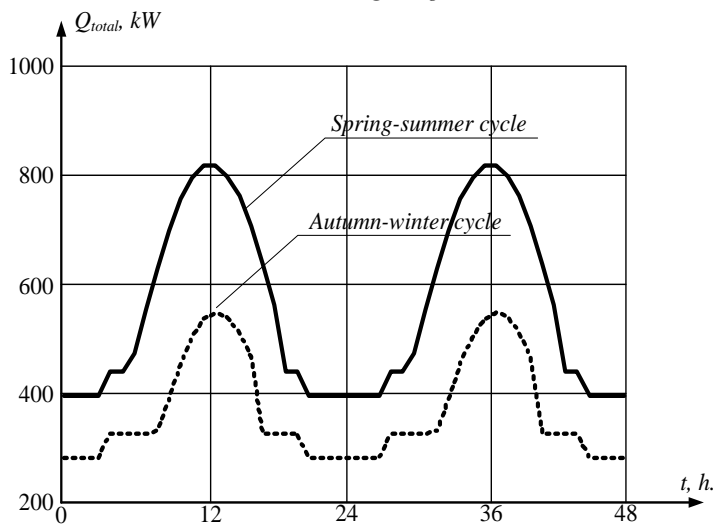

(b) during fruiting $\left(A_{g}=1500 \mathrm{~m}^{2}\right)$

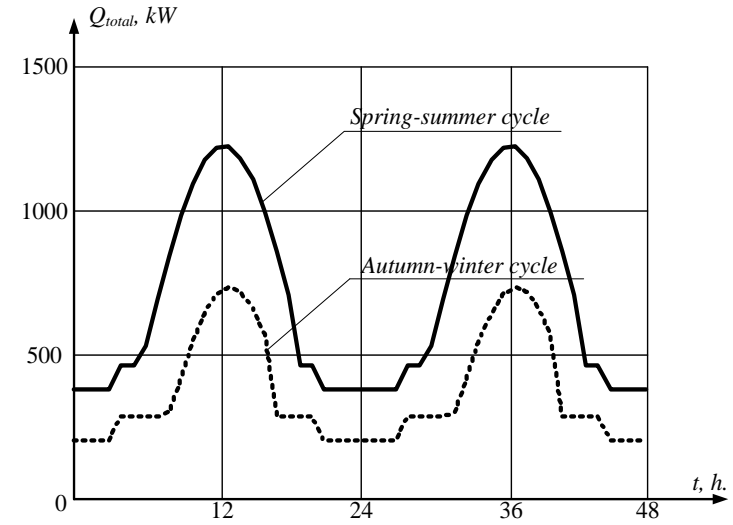

(c) before fruiting $\left(A_{g}=3000 \mathrm{~m}^{2}\right)$

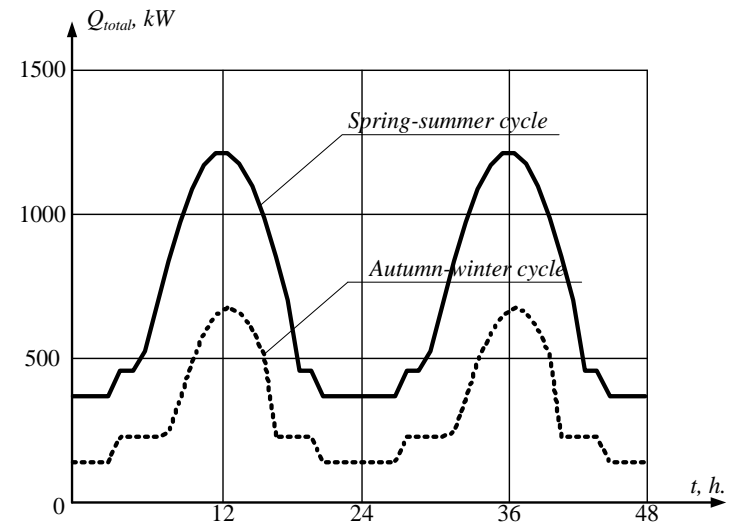

(d) during fruiting $\left(A_{g}=3000 \mathrm{~m}^{2}\right)$

Figure 7. Dependence of heat energy distribution in the greenhouse during tomato growing

332 
By analysing the results of modelling the temperature dynamics in the greenhouse growing zone, which are shown in Figures 8 and 9, the following is established:

- During the cultivation of crops in the autumn-winter cycle under the condition of the heat energy input from the sun, the heating systems and the artificial lighting systems in the amount obtained under the above climatic conditions and source parameters is insufficient, which necessitates increasing the capacity of the heating systems and prompt control of them according to the results of measuring monitoring of internal and external influencing physical and chemical parameters;

- During the cultivation of crops in the spring-summer cycle under the condition of the heat energy input from the sun, the heating systems and the artificial lighting systems, as well as total energy losses in the amount obtained by the above of parameters is overestimated, which necessitates prompt control of ventilation and shading according to the results of measuring monitoring of internal and external influential physical and chemical parameters;

- The estimated values of the constant of the total specific heat energy, which is sufficient to ensure the regulated modes of cultivation of typical greenhouse crops [28], are as follows: for cucumbers before fruiting $-24.7 \mathrm{~kW} \cdot \mathrm{m}^{-2}$, during fruiting $-25.9 \mathrm{~kW} \cdot \mathrm{m}^{-2}$; for tomatoes before fruiting $-29.6 \mathrm{~kW} \cdot \mathrm{m}^{-2}$, during fruiting $-22.2 \mathrm{~kW} \cdot \mathrm{m}^{-2}$;

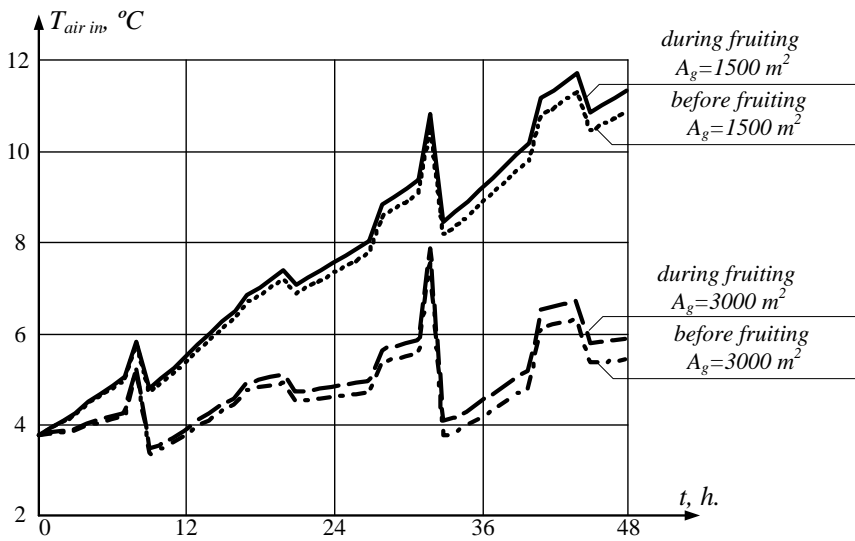

(a) Autumn-winter cycle
- Taking into account the types and periods of vegetation, seasonality and geometric dimensions of greenhouses leads to a complex function of the temperature dynamics, which makes it virtually impossible to implement control systems for growing temperatures using the classical laws of automatic control, and therefore there is a need to build subsystems for monitoring and control of air temperature in the greenhouse based on Fuzzy-logic.

\subsection{Improved functional diagram}

On the basis of the conducted research on the development of the mathematical model of measuring monitoring of air temperature in the greenhouse growing zone, the functional diagram of the measuring monitoring procedure for temperature modes of cultivation was refined, as specified in Figure 10.

Thus, the proposed functional diagram, which is shown in Figure 10, allows implementing the function of control of technological modes of cultivation, which is adaptive to types and periods of vegetation, taking into account seasonal factors and engineering design of greenhouses based on nondestructive measurement monitoring of basic characteristics of internal microclimate of greenhouses and external atmospheric parameters on a real-time basis.

Figure 8. Temperature dynamics during cucumber growing in industrial greenhouses

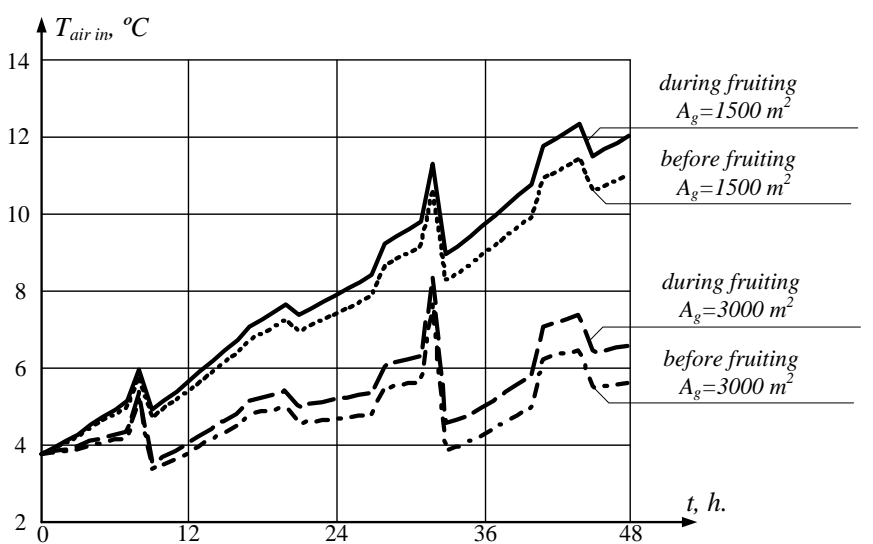

(a) Autumn-winter cycle

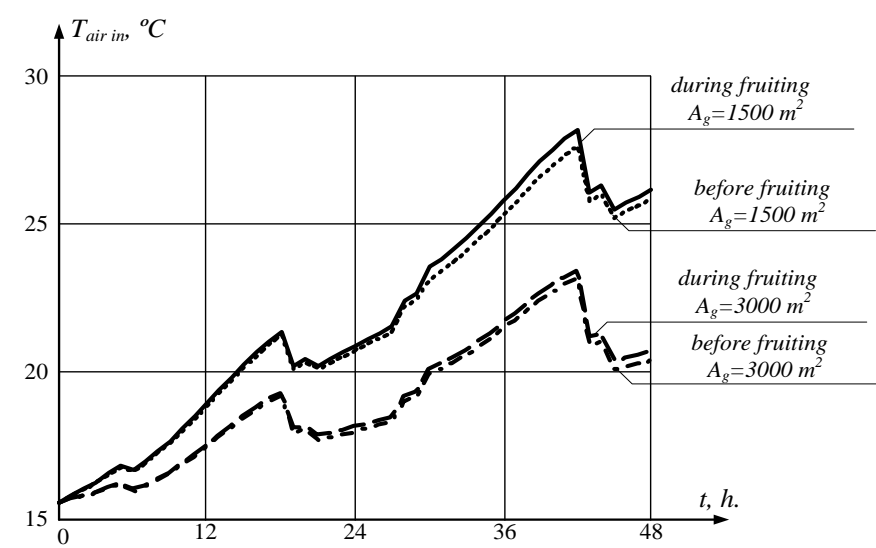

(b) Spring-summer cycle

Figure 9. Temperature dynamics during tomato growing in industrial greenhouses 


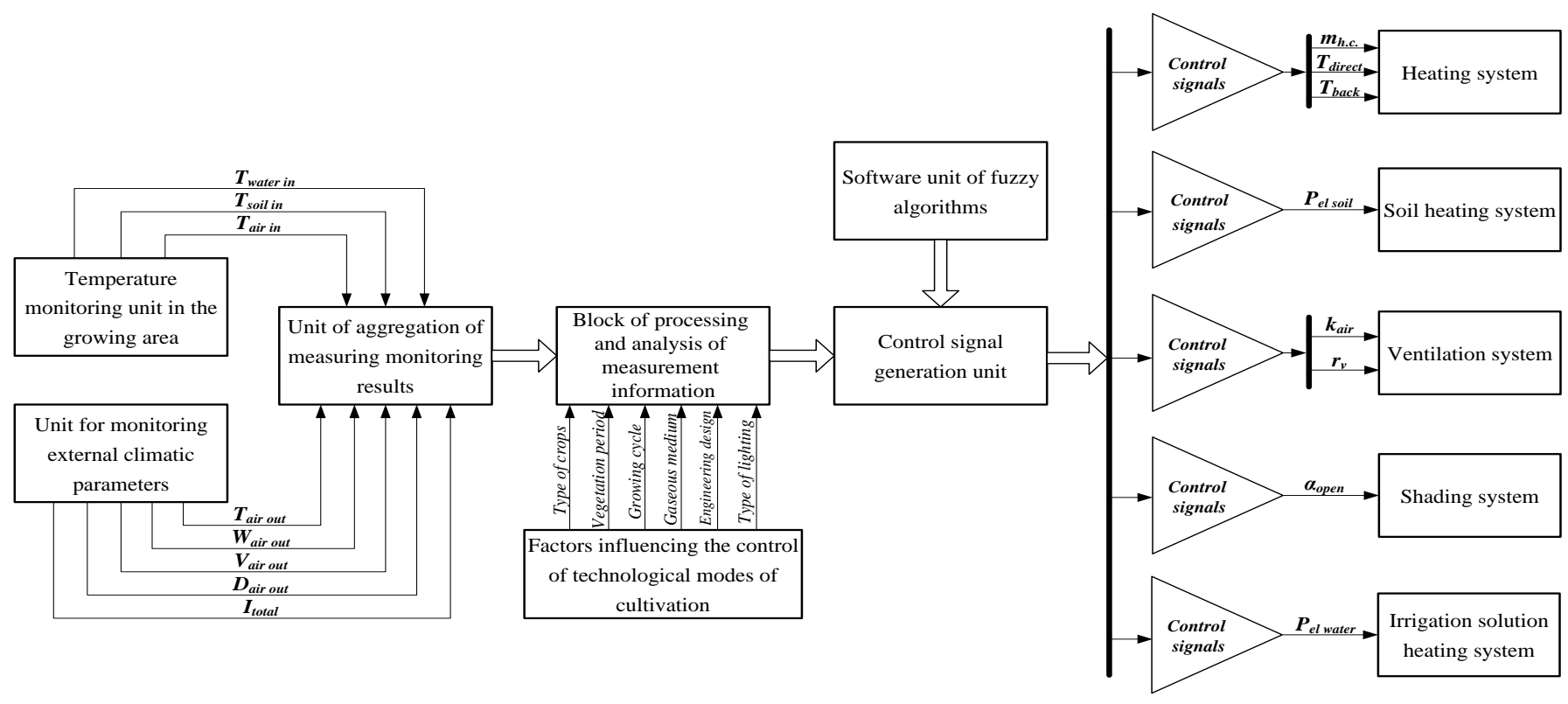

Figure 10. Refined functional diagram of measuring monitoring of the temperature modes of cultivation

\section{DISCUSSION AND SUGGESTIONS FOR FUTURE INVESTIGATIONS}

The scientific novelty of the obtained research results consists in the development of the mathematical model of the process of measuring monitoring and adaptive control of temperature modes of cultivation by taking into account the types and periods of crops, as well as seasonality and climatic features of greenhouse locations.

The practical significance of the obtained research results lies in the substantiation of the functional diagram of the process of measuring monitoring and adaptive control of the main technological processes of growing greenhouse crops.

Promising areas for further research of the developed mathematical model are: development and testing in laboratory and field conditions of hardware and software of the measuring system, which implements the proposed mathematical model; developing the control unit of technological modes of cultivation and integrating it into the system on the basis of Fuzzy-logic; comprehensive assessment of technical and economic efficiency of the implementation of research results to the production conditions of industrial greenhouse complexes.

\section{CONCLUSIONS}

The article solves the topical scientific and applied problem of improving the mathematical model of computerized measuring monitoring and control of temperature modes of cultivation in greenhouse conditions taking into account the types and periods of crop vegetation and the seasonality factor, which allowed substantiating scientific and practical provisions of greenhouse energy consumption. The main quantitative and qualitative results of the research are:

- The regularities of the influence of energy from solar radiation, energy coming from the heating system and the thermal component of energy from artificial lighting systems on the total amount of heat energy generated in the greenhouse were established;
- The possible ranges of change of the total heat energy for greenhouses with typical sizes of 1500 and $3000 \mathrm{~m}^{2}$, respectively, were estimated: from 420 to $841.1 \mathrm{~kW}$ and from $420 \mathrm{~kW}$ to $1262.2 \mathrm{~kW}$. The average rate of increase / decrease of the heat energy was also established: for the greenhouses with the area of $1500 \mathrm{~m}^{2}$ it is $46.8 \mathrm{~kW} \cdot \mathrm{h}^{-1}$; for the greenhouses with the area of $3000 \mathrm{~m}^{2}$ it is $93.6 \mathrm{~kW} \cdot \mathrm{h}^{-1}$.

- The regularities of the influence of heat losses due to the soil thermal conductivity, due to the soil absorptive capacity, heat transfer due to ventilation and infiltration and heat transfer by condensation on the total amount of the heat energy removed from the growing zone of greenhouses;

- The possible range of change in the loss of total heat energy for greenhouses with typical sizes of 1500 and 3000 $\mathrm{m}^{2}$, respectively, is: from 13.1 to $145.8 \mathrm{~kW}$ and from 26.2 $\mathrm{kW}$ to $291.6 \mathrm{~kW}$;

- The estimated ranges of constant total specific heat energy are obtained, which is sufficient to ensure the regulated modes of cultivation of typical greenhouse crops: for cucumbers before fruiting $-24.7 \mathrm{~kW} \cdot \mathrm{m}^{-2}$, during fruiting $-25.9 \mathrm{~kW} \cdot \mathrm{m}^{-2}$; for tomatoes before fruiting $-29.6 \mathrm{~kW} \cdot \mathrm{m}^{-2}$, during fruiting $-22.2 \mathrm{~kW} \cdot \mathrm{m}^{-2}$;

- The functional diagram of the measurement monitoring process was developed, which allows implementing the function of adaptive control of the technological modes of cultivation depending on the types and periods of crop vegetation, taking into account the seasonality factors and engineering design of greenhouses on a real-time basis;

- The promising areas of research on hardware and software of non-destructive computerized monitoring and control of technological modes of cultivation using methods of physical and mathematical and simulation modelling are substantiated.

\section{REFERENCES}

[1] FAO. http://www.fao.org/nutrition/education/fooddietary-guidelines/background/sustainable-dietaryguidelines/en/, accessed on April 28, 2020.

[2] Laktionov, I., Vovna, O., Zori, A. (2017). Concept of 
low cost computerized measuring system for microclimate parameters of greenhouses. Bulg. Journal of Agricultural Science, 23(4): 668-673.

[3] Laktionov, I.S., Vovna, O.V., Zori, A.A. (2017). Planning of remote experimental research on effects of greenhouse microclimate parameters on vegetable cropproducing. International Journal on Smart Sensing and Intelligent Systems, 10(4): 845-862. https://doi.org/10.21307/ijssis-2018-021

[4] Medina-Ruíz, C.A., Mercado-Luna, I.A., Soto-Zarazúa, G.M., Torres-Pacheco, I., Rico-García, E. (2011). Mathematical modeling on tomato plants: A review. African Journal of Agricultural Research, 6(33): 67456749. https://doi.org/10.5897/AJARX11.001

[5] Hemming, S., de Zwart, F., Elings, A., Righini, I., Petropoulou, A. (2019). Remote control of greenhouse vegetable production with artificial intelligencegreenhouse climate, irrigation, and crop production. Sensors, 19(8): 1-22. https://doi.org/10.3390/s19081807

[6] Caicedo-Ortiz, J.G., De-la-Hoz-Franco, E., Ortega, R.M., Pineres-Espitia, G., Combita-Nino, H., Estevez, F., Cama-Pinto, A. (2018). Monitoring system for agronomic variables based in WSN technology on cassava crops. Computers and Electronics in Agriculture, 145: 275-281. https://doi.org/10.1016/j.compag.2018.01.004

[7] Sanchez-Molina, J.A., Ming, L., Rodriguez, F., Guzman, J.L., Hui, W., Ya, X. (2017). Development and test verification of air temperature model for Chinese solar and Spainish Almeria-type greenhouses. Int J Agric \& Biol. $\quad$ Eng., 10(4): 66-76. https://doi.org/10.25165/j.ijabe.20171004

[8] Ben Ali, R., Aridhi, E., Mami, A. (2015). Dynamic model of an agricultural greenhouse using MatlabSimulink environment. In: $16^{\text {th }}$ International Conference on Sciences and Techniques of Automatic Control and Computer Engineering (STA), Monastir, pp. 346-350. https://doi.org/10.1109/STA.2015.7505185

[9] Riahi, J., Vergura, S., Mezghani, D., Mami, A. (2020). Intelligent control of the microclimate of an agricultural greenhouse powered by a supporting PV system. Appl. Sci., 10(4): 1350. https://doi.org/10.3390/app10041350

[10] Shen, Y., Wei, R., Xu, L. (2018). Energy consumption prediction of a greenhouse and optimization of daily average temperature. Energies, 11(65): 1-17. https://doi.org/10.3390/en11010065

[11] Atia, D.M., El-madany, H.T. (2017). Analysis and design of greenhouse temperature control using adaptive neuro-fuzzy inference system. Journal of Electrical Systems and Information Technology, 4(1): 34-48. https://doi.org/10.1016/j.jesit.2016.10.014

[12] Faouzi, D., Bibi-Triki, N., Benmoussa, N., Bouhdjar, A., Abène, A. (2017). Optimizing the management and use of energy in the greenhouse by modeling the associated heating and cooling systems and implemented by an intelligent controller. International Journal of Computer Science and Technology, 8(2): 121-129.

[13] Mostakim, N., Mahmud, S., Jewel, K.H. (2020). A simulation based study of a greenhouse system with intelligent fuzzy logic. International Journal of Fuzzy $\begin{array}{lll}\text { Logic } & \text { Systems, } & 10(1) \text { : }\end{array}$ https://doi.org/10.5121/ijfls.2020.10102

[14] Laktionov, I., Vovna, O., Cherevko, O., Kozlovskaya, T. (2018). Mathematical model for monitoring carbon dioxide concentration in industrial greenhouses. Agronomy Research, 16(1): 134-146. https://doi.org/10.15159/AR.17.074

[15] Laktionov, I.S., Vovna, O.V., Zori, A.A., Lebediev, V.A. (2018). Results of simulation and physical modeling of the computerized monitoring and control system for greenhouse microclimate parameters. International Journal on Smart Sensing and Intelligent Systems, 11(1): 1-15. https://doi.org/10.21307/ijssis2018-017

[16] Vovna, O.V., Laktionov, I.S., Koyfman, O.O., Stashkevych, I.I., Lebediev, V.A. (2020). Study of metrological characteristics of low-cost digital temperature sensors for greenhouse conditions. Serbian Journal of Electrical Engineering, 17(1): 1-20. https://doi.org/10.2298/SJEE2001001V

[17] Ehret, D.L., Hill, B.D., Helmer, T., Edwards, D.R. (2011). Neural network modeling of greenhouse tomato yield, growth and water use from automated crop monitoring data. Computers and Electronics in Agriculture, $\quad 79(1)$ : 82-89. https://doi.org/10.1016/j.compag.2011.07.013

[18] Boote, K.J., Rybak, M.R., Scholberg, J.M., Jones, J.W. (2012). Improving the CROPGRO-Tomato model for predicting growth and yield response to temperature. HortScience, 47(8): 1038-1049. https://doi.org/10.21273/HORTSCI.47.8.1038

[19] Jones, J.W., Dayan, E., Allen, L.H., van Keulen, H., Challa, H. (1991). A dynamic tomato growth and yield model (TOMGRO). Transactions of the American Society of Agricultural and Biological Engineers, 34(2): 663-671. https://doi.org/10.13031/2013.31715

[20] Wang, J., Zhou, J., Gu, R., Chen, M., Li, P. (2018). Manage system for internet of things of greenhouse based on GWT. Information Processing in Agriculture, $5(2)$ :

269-278. https://doi.org/10.1016/j.inpa.2018.01.002

[21] Kitpo, N., Kugai, Y., Inoue, M., Yokemura, T., Satomura, S. (2019). Internet of things for greenhouse monitoring system using deep learning and bot notification services. In 2019 IEEE International Conference on Consumer Electronics (ICCE), Las Vegas, NV, USA, pp. 1-4. https://doi.org/10.1109/ICCE.2019.8661999

[22] Druma, A.M. (1998). Dynamic Climate Model of a Greenhouse. Report Geothermal Training Programme No. 3. The United Nations University, Reykjavik, Iceland.

[23] Emeish, M. (1999). Geothermal Heating System for Jordanian Greenhouses. Report 2 of Geothermal Training Programme. The United Nations University, Reykjavik, Iceland.

[24] Hanan, J.J. (1998). Greenhouses: Advanced Technology for Protected Horticulture. Boca Raton: CRC Press.

[25] Popovski, K., Popovska-Vasilevska, S. (1993). Heating greenhouses with geothermal energy. In: International Summer School, Skopje, pp. 1-17.

[26] Air Conditioning and Ventilation. https://www.hvacschool.ru/biblioteka/tepl_balans/metodika_rascheta/tepl oti_pomeshhen/, accessed on April 24, 2020.

[27] Kittas, C., Boulard, T., Papadakis, G. (1997). Natural ventilation of a greenhouse with ridge and side openings: sensitivity to temperature and wind effects. Am. Soc. Agric. Biol. Eng., 40: 415-425. 
https://doi.org/10.13031/2013.21268.

[28] Baudoin, W., Nersisyan, A., Shamilov, A., Hodder, A., Gutierrez, D., de Pascale, S., Nicola, S., Gruda, N., Urban, L., Tanny, J. (2017). Good Agricultural Practices for greenhouse vegetable production in the South East European countries. Rome: FAO.

\section{NOMENCLATURE}

$A_{g} \quad$ greenhouse surface area (roof and side walls), $\mathrm{m}^{2}$

$C_{c} \quad$ condensation rate on the surface of the greenhouse, $\mathrm{kg} \cdot \mathrm{s}^{-1} \cdot \mathrm{m}^{-2}$

ch.c. specific heat of the heat carrier, $\mathrm{J} \cdot \mathrm{kg}^{-1 .{ }^{\circ} \mathrm{C}^{-1}}$

$C_{\rho} \quad$ specific heat of air, $\mathrm{J} \cdot \mathrm{kg}^{-1 .}{ }^{\circ} \mathrm{C}^{-1}$

$D_{\text {air out }} \quad$ ambient air flow velocity, dimensionless

$E_{l} \quad$ required level of illumination of the growing area, $1 \mathrm{x}$

$F_{l}$

$F_{v} \quad$ air flow due to ventilation, $\mathrm{m}^{3} \cdot \mathrm{s}^{-1}$

$h \quad$ heat transfer coefficient, $\mathrm{W} \cdot \mathrm{m}^{-2 .}{ }^{\circ} \mathrm{C}^{-1}$

$I_{s c} \quad$ solar constant, $\mathrm{W} \cdot \mathrm{m}^{-2}$

Itotal solar energy falling on the greenhouse surface, $\mathrm{W} \cdot \mathrm{m}^{-2}$

$k_{\text {air }} \quad$ multiplicity of air exchange, $\mathrm{h}^{-1}$

$k_{\text {decr }} \quad$ coefficient of attenuation of solar radiation, dimensionless

$k_{g} \quad$ soil thermal conductivity coefficient, $\mathrm{W} \cdot \mathrm{m}^{-1 .}{ }^{\circ} \mathrm{C}^{-1}$

$L_{v} \quad$ enthalpy of saturated steam, $\mathrm{J} \cdot \mathrm{kg}^{-1}$

$m_{\text {h.c. }} \quad$ Heat carrier consumption, $\mathrm{kg} \cdot \mathrm{s}^{-1}$

$n \quad$ continuous number of the day in the calendar year, dimensionless

$P_{\text {el soil }} \quad$ electric power consumption by the ground heating system, $\mathrm{W}$

$P_{\text {el water }} \quad$ electric power consumption by heating the solution of the heating system, $\mathrm{W}$

$Q_{c} \quad$ heat transfer through condensation, W

$Q_{g} \quad$ heat loss due to the soil absorptive capacity, W

$Q_{\text {gain }}$

$Q_{h}$

$Q_{i}$ W

heat energy coming from the heating system, W

heat transfer due to infiltration, $\mathrm{W}$ $q_{l}$

$Q_{\text {loss }}$

$Q_{s}$

$Q_{\text {total }}$

$Q_{v}$

$Q_{v+i}$

$r_{v}$

$t$

$T_{\text {air in }}$

$T_{\text {air ou }}$

$T_{\text {back }}$

$T_{\text {direct }}$

$T_{\text {soil }}$

$T_{\text {water in }}$

$V_{g}$

$V_{\text {in }}$

$v_{\text {air in }}$

vair out

$W_{\text {air out }}$

$Z_{g}$

\section{Greek symbols}

$\alpha_{\text {open }} \quad$ angle of opening of the mechanisms of the shading system, degree

$\gamma$

$\eta_{l}$

$\rho_{\text {air }}$

$\tau$

$\omega$

\section{Subscripts}

heat loss due to thermal conductivity, $\mathrm{W}$ thermal component of energy from the artificial lighting systems, $\mathrm{W}$

specific heat release indicator, $\mathrm{W} \cdot \mathrm{xx}^{-1} \cdot \mathrm{m}^{-2}$

amount of energy consumed in the greenhouse, $\mathrm{W}$

useful solar energy entering the greenhouse, $\mathrm{W}$

total heat energy in the growing area, $\mathrm{W}$

heat transfer through ventilation, $\mathrm{W}$

total heat transfer due to condensation and infiltration, $\mathrm{W}$

percentage of opening of mechanisms of ventilation system, dimensionless

time, $\mathrm{h}$.

temperature inside the greenhouse, ${ }^{\circ} \mathrm{C}$

ambient temperature, ${ }^{\circ} \mathrm{C}$

temperature of the heat carrier removed from the heating system, ${ }^{\circ} \mathrm{C}$

heat carrier supply temperature, ${ }^{\circ} \mathrm{C}$

soil temperature, ${ }^{\circ} \mathrm{C}$

temperature of irrigation solution, ${ }^{\circ} \mathrm{C}$

greenhouse volume, $\mathrm{m}^{3}$

volume of the greenhouse growing zone, $\mathrm{m}^{3}$ air flow velocity, $\mathrm{m} \cdot \mathrm{s}^{-1}$

ambient air velocity, $\mathrm{m} \cdot \mathrm{s}^{-1}$

ambient humidity, \%

thickness of the soil layer, $m$

\section{$\max$}

norm

maximum value of the physical quantity

physical quantity normalized to the maximum value 